\title{
Rate of transport of L-arginine is independent of the expression of inducible nitric oxide synthase in HEK 293 cells
}

\author{
Zhaoqiang Cui ${ }^{\mathrm{a}}$, Raj Tuladhar ${ }^{\mathrm{a}}$, Stephen L. Hart ${ }^{\mathrm{b}}$, Michael S. Marber ${ }^{\mathrm{c}}$, \\ Jeremy D. Pearson ${ }^{\mathrm{d}}$, Anwar R. Baydoun ${ }^{\mathrm{a}, *}$ \\ ${ }^{a}$ Department of Biosciences, University of Hertfordshire, College Lane, Herts AL10 9AB, UK \\ ${ }^{\mathrm{b}}$ Instituteof Child Health, University College London, London WC1N 1 EH, UK \\ ${ }^{\mathrm{c}}$ Department of Cardiology, King's College London, The Rayne Institute, St. Thomas' Hospital, London SE1 7EH, UK \\ ${ }^{\mathrm{d}}$ Centre for Cardiovascular Biology and Medicine, School of Biomedical Sciences, King's College London, Guy's Campus, London SE1 1UL, UK
}

Received 30 July 2004; revised 19 October 2004

\section{Abstract}

Expression of inducible nitric oxide synthase (iNOS) is generally accompanied by a parallel upregulation in L-arginine transport which is dependent, at least in part, on the synthesis of new carrier proteins. It is not clear however whether the induction of iNOS and its subsequent utilisation of L-arginine for NO synthesis contribute to the enhancement in L-arginine transport rates observed following induction of cells with pro-inflammatory mediators. To address this issue, we have transfected an iNOS construct in a pEGFP-N1 vector into HEK-293 cells and investigated the effects this has on L-arginine transport. The expression of iNOS through transfection resulted in the production of significant quantities of NO as detected by the standard Griess assay. Under these conditions, the transport of L-arginine was found to be unaltered, with rate of uptake being comparable in both transfected and non-transfected cells. Characterisation of the transporter(s) involved with uptake of L-arginine revealed features characteristic of the classical cationic amino acid transport system $\mathrm{y}^{+}$. Further analysis of the expression profile of the cationic amino acid transporter (CAT) involved revealed the presence of transcripts for CAT-1 and CAT-2B. These data demonstrate that iNOS activity does not drive or enhance L-arginine transport despite the fact that HEK-293 cells transport L-arginine via the CATs, including CAT-2B which is thought to be critical for supply of substrate to iNOS.

(C) 2004 Published by Elsevier Inc.

Keywords: L-Arginine transport; Cationic amino acid transporters; Nitric oxide; Inducible nitric oxide synthase; HEK293 cells

Expression of inducible nitric oxide synthase (iNOS) in various cells and tissues is associated with the overproduction of nitric oxide (NO) which although critical for immune defences also functions as an important mediator of inflammatory responses with detrimental consequences. For instance, iNOS produced NO is believed to be responsible for the systemic hypotension seen in septic shock [1-3] and has been implicated in the pathogenesis of several other inflammatory diseases,

\footnotetext{
${ }^{*}$ Corresponding author. Fax: +01707 285046.

E-mail address: a.baydoun@herts.ac.uk (A.R. Baydoun).
}

including asthma [4] and inflammatory bowel disease [5]. 38 Once expressed, synthesis of NO by iNOS is critically 39 dependent on the availability and transport of L-arginine 40 [6-10]. The induction of iNOS by pro-inflammatory 41 mediators is accompanied by a parallel upregulation in 42 L-arginine transport [7,11-13] which is due at least in 43 part to enhanced expression of transcripts for cationic 44 amino acid transporters (CATs), including CAT-1, 2B, 45 and potentially $2 \mathrm{~A}[14,15]$. This parallel upregulation in 46 CAT expression and activity provides a mechanism for 47 sustaining substrate supply during enhanced synthesis of 48 NO by iNOS. It is not known, however, whether the 49 expression of iNOS and the subsequent enhanced utilisa- 50 
tion of L-arginine by this enzyme directly regulate CAT expression and function. One report in the literature has indicated that inhibition of iNOS activity using either 2amino-5,6-dihydro-6-methyl-4H-1,3-thiazine (AMT), a potent and selective inhibitor of iNOS [16] or $S$-ethylisothiourea, a potent but non-selective NOS inhibitor [17], abolished LPS-induced L-arginine transport [18]. The same group has also demonstrated that expression of both iNOS and CAT-2B mRNA may be downregulated after prolonged $(20 \mathrm{~h})$ exposure of rat alveolar macrophages to dexamethasone. These effects were accompanied by corresponding decreases in both LPSstimulated nitrite production and $\mathrm{L}_{\mathrm{L}}\left[{ }^{3} \mathrm{H}\right]$ arginine transport, suggesting a parallel regulation of the expression and function of iNOS and CAT-2B, at least in rat alveolar macrophages [19]. These finding are, however, at odds with previous studies in the murine macrophage J774 cell line [20] and in rat cultured aortic smooth muscle cells [13,21] in which dexamethasone selectively blocked iNOS expression whilst having no effect on induced L-arginine transport, suggesting that upregulation of transport may be independent of iNOS activity. These studies did not however take into account the fact that other pathways which utilise L-arginine may also be switched on in activated cells, thus masking any direct coupling between utilisation of L-arginine by iNOS and the subsequent regulation of transport that may occur as a consequence of the activity of this enzyme.

To determine unequivocally whether CAT function is influenced by the activity of iNOS we therefore deliberately chose to use an experimental system in which iNOS could be expressed and was fully active in cells in the absence of pro-inflammatory stimuli. Transient iNOS expression was therefore induced by transfection in human embryonic kidney-293 (HEK-293 cells). These cells can be easily transfected but do not express endogenous iNOS or show any upregulation in CAT activity following exposure to the standard cocktail of bacterial lipopolysaccharide (LPS) and cytokines generally used to induce these pathways in other cells (unpublished observations). In parallel studies, the characteristics of Larginine transport have been fully investigated and the nature of the transporters involved with L-arginine uptake established. These studies are essential since very little is currently known about the mechanism of entry of L-arginine into HEK293 cells. Moreover, the transporters expressed may potentially determine the manner in which NO synthesis is regulated in these cells.

\section{Experimental procedure}

\section{Materials}

Tissue culture reagents were obtained from Invitrogen (Paisley, UK). Other reagents used were: SMART
RACE cDNA Amplification Kit (BD Biosciences Clon- 107 tech, Cowley, UK); Eukaryotic TOPO TA Cloning Kit 108 and competent Escherichia coli (Invitrogen, Paisley, 109 UK); PCR primers (MWG Biotech, Milton Keynes, 110 UK); Restriction enzymes and T4 DNA ligase (Pro- 111 mega, Southampton, UK); Taq DNA Polymerase, M- 112 MLV reverse Transcriptase, and dNTP (Invitrogen, 113 Paisley, UK); Plasmid miniprep and maxiprep kits 114 (Qiagen, Crawley, UK); anti-iNOS and anti-GFP mono- 115 clonal antibodies (BD Biosciences Clontech, Cowley, 116 UK). L- $\left[2,3-{ }^{3} \mathrm{H}\right]$ arginine $(36.1 \mathrm{Ci} / \mathrm{mmol})$ was obtained 117 from New England Nuclear (Dreieich, Germany). 118 Bicinchoninic acid (BCA) protein assay reagent was 119 from Pierce (Perbio Science UK, Cheshire, UK). 120 GW274150 was a gift from GlaxoSmithKline (Steve- 121 nage, UK). All other chemicals were obtained from 122 Sigma or BDH and were of the highest analytical grade 123 obtainable.

Cell culture

HEK-293 cells were maintained in Dulbecco's modi- 128 fied Eagle's medium (DMEM) supplemented with peni- 129 cillin $\left(100 \mathrm{U} \mathrm{ml}^{-1}\right)$, streptomycin $\left(100 \mu \mathrm{g} \mathrm{ml}^{-1}\right)$, and $10 \% 130$ foetal bovine serum. Cells were harvested by trypsinisa- 131 tion and passaged every 5 days by dilution of a suspen- 132 sion of the cells $1: 4$ in fresh medium.

\section{RNA isolation}

Total cellular RNA was isolated from the cultured 137 cells using RNA STAT-60 (Biogenesis, Poole, UK) 138 according to the manufacturer's protocol. The concen- 139 tration of RNA solutions was determined spectrophoto- 140 metrically and the quality verified by visualisation of $28 \mathrm{~S} 141$ and 18S rRNA bands after electrophoresis through a 1\% 142 ethidium bromide stained agarose gel. 143

Construction of iNOS-pEGFP-N1 Plasmid 145

Total RNA was extracted from rat (Wistar) cultured 147 aortic smooth muscle cells activated with bacterial lipo- 148 polysaccharide (LPS; $100 \mu \mathrm{g} \mathrm{ml}^{-1}$ ) and interferon- $\gamma 149$ (IFN- $\gamma ; 50 \mathrm{U} \mathrm{ml}^{-1}$ ) for $24 \mathrm{~h}$. The first strand cDNA was 150 synthesised from $1 \mu \mathrm{g}$ total RNA using the Clontech 151 SMART system (BD Biosciences Clontech, Cowley, 152 UK) and an iNOS gene-specific reverse primer (5'-GAG 153 TCT TGT GCC TTT GGG CT-3') based on a pub- 154 lished rat iNOS cDNA sequence (Accession No.: 155 X76881). The cDNA products were subsequently ampli- 156 fied by PCR using the SMART RACE cDNA Amplifi- 157 cation Kit together with the above reverse primer, 158 lacking the nucleotide sequence for the iNOS stop 159 codon. To facilitate translation initiation and enhance 160 iNOS-GFP expression levels, a modified iNOS forward 161 primer was designed with a Kozak consensus sequence 162 
introduced around the initiation codon of iNOS (5'CAC CGC CAT GGC TTG CCC CTG GAA-3'). A $3.449 \mathrm{~kb}$ cDNA fragment amplified was ligated into pcDNA3.1 using the Eukaryotic TOPO TA Cloning Kit. After transformation into E. coli, a mini-preparation of the plasmid was made and the purified cDNA sequenced using a Beckman Coulter CEQ2000XL Sequencer. The iNOS-GFP expression vector was subsequently constructed by digesting pcDNA 3.1 harbouring the iNOS cDNA with HindIII and SacII, and then subcloning the restricted iNOS cDNA from pcDNA3.1 into the HindIII and SacII sites of the pEGFP-N1 vector. The iNOS sequence was fused at its C terminal to GFP and was driven directly by the CMV promoter of the plasmid.

\section{Transfection of HEK293 cells with iNOS-pEGFP-N1}

Confluent monolayers of HEK-293 cells in T75 tissue culture flasks were trypsinised and plated into 24-well plates at a seeding density of $2 \times 10^{4}$ cells per well. Cells were allowed to grow to $60 \%$ confluency prior to transfecting with iNOS-pEGFP-N1 using an $\alpha 5 \beta 1$ integrinbinding polycationic peptide $\left([\mathrm{K}]_{16}\right.$ GACRRETAWA CG; Peptide 6) [22]. For optimum transfection efficiency, conditions previously described [22] were adhered to. Briefly, culture medium was removed from wells and the adherent cells washed twice with PBS. $0.5 \mathrm{ml}$ of transfection complex in Opti-MEM I medium containing lipofectin $(0.75 \mu \mathrm{l})$, plasmid $(1 \mu \mathrm{g})$, and peptide $6(4 \mu \mathrm{g})$ was then added to each well. Cells were incubated for a further $3 \mathrm{~h}$ at $37^{\circ} \mathrm{C}$, after which the medium was removed, replace with normal culture medium containing $10 \%$ FCS and incubated in a tissue culture incubator at $37^{\circ} \mathrm{C}$ for $6-48 \mathrm{~h}$ before determining accumulated nitrite levels in the culture medium as described below. In parallel experiments cells were also incubated with the potent and highly selective iNOS inhibitor GW274150 (S-[2-[(1iminoethyl)amino]ethyl]-L-homocysteine) to inhibit NO production [23]. In control experiments cells were transfected with either empty vector or pEGF-N1 vector alone. Transfected cells were routinely visualised using a Nikon EFD 3 Labophot-2 fluorescence microscope and the transfection efficiency determined from the proportion of green fluorescing cells. The estimated transfection efficiency generally obtained with the above protocol was between 60 and $70 \%$. Batches of cells showing $<50 \%$ transfection were discarded. There was no detectable fluorescence in cells transfected with the empty nonGFP vector alone.

\section{Western blot analysis of iNOS expression}

Western blotting was carried out as described previously [24]. Cell lysates ( $20 \mu \mathrm{g}$ protein per lane) were separated by SDS-PAGE electrophoresis, transferred onto PVDF membrane (Sigma-Aldrich, Poole, UK) and blocked for $2 \mathrm{~h}$ in $100 \mathrm{mM} \mathrm{NaCl}, 10 \mathrm{mM}$ Tris, $0.1 \%$ (v/v) 219 Tween 20, pH 7.4 (STT), containing 5\% (w/v) non-fat 220 milk. Membranes were then incubated overnight with 221 either a monoclonal anti-iNOS (1:2500 dilution) or anti- 222 GFP (1:1000 dilution) antibody in STT containing 5\% 223 $(\mathrm{w} / \mathrm{v})$ non-fat milk). Blots were washed with STT 224 $(6 \times 5 \mathrm{~min})$ and incubated with a 1:10,000 dilution of 225 horseradish peroxidase-conjugated goat anti-mouse 226 antibody for $1 \mathrm{~h}$. Following further washing $(6 \times 5 \mathrm{~min}) 227$ in STT, immunoreactive bands were visualised using 228 ECL detection System (Amersham-Pharmacia, Buck- 229 inghamshire, UK). 230

231

Measurement of nitrite formation $\quad 232$

Measurement of nitrite production as an assay of NO 234 release was carried out as described previously [24] using 235 the Griess reaction with sodium nitrite as standard [25]. 236

Measurement of L-arginine transport 238

Unidirectional transport of L-arginine was measured 240 in cell monolayers as described previously [20]. Cells 241 were rinsed twice with a modified Hepes-buffered Krebs 242 solution (composition $(\mathrm{mM}): \mathrm{NaCl}, 131 ; \mathrm{KCl}, 5.5 ; 243$ $\mathrm{MgCl}_{2}, 1 ; \mathrm{CaCl}_{2}, 2.5 ; \mathrm{NaHCO}_{3}, 25 ; \mathrm{NaH}_{2} \mathrm{PO}_{4}, 1 ;$ D-glu- 244 cose, 5.5; Hepes, 20; $\mathrm{pH} 7.4$ ) at $37^{\circ} \mathrm{C}$. Uptake was initi- 245 ated by adding $50 \mu \mathrm{l}$ of Krebs containing either $100 \mu \mathrm{M} 246$ or increasing concentrations $(10-1000 \mu \mathrm{M})$ of L- $\left[{ }^{3} \mathrm{H}\right]$ argi- 247 nine $\left(2 \mu \mathrm{Ci} \mathrm{ml}^{-1}\right)$ to each well and influx measured over 248 $1 \mathrm{~min}$. The effects of $\mathrm{pH}$ on transport were examined in 249 Krebs solution with $\mathrm{pH}$ values ranging between $\mathrm{pH} 6250$ and 7.4. In parallel experiments, the sodium-dependency 251 of transport was examined in modified buffer in which 252 $\mathrm{NaCl}, \mathrm{NaHCO}_{3}$, and $\mathrm{NaH}_{2} \mathrm{PO}_{4}$ were replaced with cho- 253 line chloride, choline bicarbonate, and $\mathrm{KH}_{2} \mathrm{PO}_{4}$, respec- 254 tively. Uptake of $\mathrm{L}-\left[{ }^{3} \mathrm{H}\right]$ arginine was terminated by 255 placing plates on ice and rinsing cells twice with $200 \mu 1256$ ice-cold Krebs containing $10 \mathrm{mM}$ unlabelled L-arginine. 257 Cell protein was determined using bicinchoninic acid 258 (BCA) protein assay reagent following the manufac- 259 turer's protocol. Radioactivity (dpm) in cell lysates was 260 measured by liquid scintillation counting. Transport was 261 expressed in pmol $\mu$ g protein ${ }^{-1} \mathrm{~min}^{-1}$. 262

Profile of CAT expression in HEK-293 cells 264

The identification of the CATs expressed in HEK-293 266 cells was determined by RT-PCR. The first-strand 267 cDNA was synthesised from $2 \mu \mathrm{g}$ total RNA using $0.5 \mu 1268$ $(250 \mathrm{ng})$ random hexamer primers, $1 \mu \mathrm{l}$ M-MLV reverse 269 transcriptase $(200 \mathrm{U} / \mu \mathrm{l}), 1 \mu \mathrm{lNTP}(10 \mathrm{mM}), 4 \mu \mathrm{l}$ of $5 \times 270$ first-strand buffer, $2 \mu$ dithiothreitol $(0.1 \mathrm{M}), 1 \mu$ l RNase- 271 OUT $(40 \mathrm{U} / \mu \mathrm{l})$, and $9 \mu \mathrm{l}$ sterile distilled water. The reac- 272 tion was allowed to proceed according to the supplier's 273 recommendation (Invitrogen, Paisley, UK) for M-MLV 274 
reverse transcreptase. The cDNA product was amplified by PCR using CAT-specific primers designed from Genbank sequences for human CAT-1 (Accession No.: NM_003045), CAT-2 A (Accession No.: U76368), and CAT-2B (Accession No.: D29990). The following primer pairs were used: hCAT-1 (656bp), 5'-TCG GCC ATG GTC AAC AAA AT-3' and 5'-TCA AAG AGG AAG GCC ATC ACA-3'; hCAT-2A (599 bp), 5'-GAG TCT GCT TGG GTG AAT AAA-3' and $5^{\prime}$-GAC TGC CTC TTA CTC ACT CT-3'; and hCAT-2B (642 bp), 5'-GAG TCT GCT TGG GTG AAT AAA- $3^{\prime}$ and $5^{\prime}$-AGC TGC CAC TGC ACC CGA TGA-3'. Amplification was carried out in a Techne touchgene programmable thermal cycler (Techne, Cambridge, UK) using Taq DNA polymerase $(0.5 \mathrm{U})$. The reaction mixture $(0.5 \mu \mathrm{l}$ of a $10 \mu \mathrm{M}$ stock of each primer, $0.5 \mu \mathrm{l}$ of dNTP $(10 \mathrm{mM}), 2.5 \mu \mathrm{l}$ of $10 \times$ PCR buffer, $0.75 \mu \mathrm{l}$ of $50 \mathrm{mM} \mathrm{MgCl}_{2}$, and $19.75 \mu \mathrm{l}$ sterile distilled water) was initially heated to $94^{\circ} \mathrm{C}$ for 2 min, followed by 33 cycles under the following conditions: denaturing at $94^{\circ} \mathrm{C}$ for $30 \mathrm{~s}$, annealing at $55^{\circ} \mathrm{C}$ for $40 \mathrm{~s}$, extension at $72^{\circ} \mathrm{C}$ for $40 \mathrm{~s}$, and a final extension step at $72^{\circ} \mathrm{C}$ for $5 \mathrm{~min}$. Ten microliters of the PCR product was used for DNA electrophoresis on a $1 \%$ agarose gel, stained with ethidium bromide, and documented using a Bio-Rad imager system.

\section{Statistics}

All values are means $\pm \mathrm{SE}$ of measurements in at least three different cell cultures with two replicates per experiment. ANOVA was used to determine statistical significance between paired values with the overall confidence levels set at $95 \%(0.05)$.

\section{Results}

Cloning, sequence, and analysis of iNOS cDNA

A $3.449 \mathrm{~kb}$ cDNA fragment was amplified by PCR as described in methods using iNOS gene specific primers and the sequence obtained submitted to GenBank (Accession No.: AY211532). The cDNA produced encodes the full-length iNOS protein when inserted into the multiple cloning site of the pEGP-N1 plasmid and driven by the CMV promoter of the plasmid. The first six bases at the $5^{\prime}$ end of the cDNA produced were not

part of the iNOS sequence. Instead, these six bases con- 331 stituted the Kozak consensus translation initiation site 332 for iNOS. The remaining sequence represents that for 333 iNOS. Sequence comparison revealed our cloned iNOS 334 cDNA to be highly homologous $(>99.5 \%)$ with two 335 other published rat iNOS sequences, showing 17 single- 336 base mismatches to that published by Nunokawa et al. 337 [26, Accession No.: D14051], and 13 single-base mis- 338 matches to the sequence published by Geng et al. [27, 339 Accession No.: X76881]. These small differences occur 340 as sporadically placed amino acid substitutions (Fig. 1) 341 with no insertion or deletion mutations being apparent 342 between the clones. Our cDNA also shows a high level 343 of homology at the cDNA level to the inducible enzyme 344 from human [28] and mouse [29]. It contains a single 345 open reading frame beginning with an AUG methio- 346 nine at codon 1 and encodes a protein of 1147 residues 347 with a calculated molecular mass of $130.67 \mathrm{kDa}$. It also 348 contains the predicted consensus recognition sites for 349 the various cofactors including FMN (at amino acids: 350 620-639), FAD-PPi (at amino acids: 764-777), FAD- 351 ISO (at amino acids: 900-910), NADPH-Ribose (at 352 amino acids: 973-992), and NADPH-Ade (at amino 353 acids: 1074-1088) in the C-terminal and for calmodu- 354 line (at amino acids 502-527) in the mid portion. Fol- 355 lowing sequencing and analysis, the fragment produced 356 was subsequently subcloned into the HindIII and SacII 357 sites of the pEGFP-N1 vector and used in expression 358 studies. 359

Efficiency of transfection of iNOS using peptide 6

Transfection of HEK-293 cells with iNOS-pEGFP- 363 N1 using peptide 6 under optimised conditions reported 364 previously [22] resulted in detectable expression of GFP 365 in $60-70 \%$ of cells. As shown in Fig. 2, visualisation of 366 transfected cells by fluorescence microscopy confirms 367 significant expression of GFP at 6 h (Fig. 2A) with levels 368 increasing over time, reaching a peak at $24-48 \mathrm{~h}$ (Fig. 369 2D) but declining by $72 \mathrm{~h}$ due to marked decreases in cell 370 viability (data not shown).

Western blot analysis of lysates carried out in parallel 372 reflects a time-dependent expression of GFP which as 373 shown in Fig. 3A, was detectable after $6 \mathrm{~h}$, peaking at 374 $24 \mathrm{~h}$. Expression of iNOS was evident after $6 \mathrm{~h}$ and was 375 maximal at $12 \mathrm{~h}$ remaining at this level over the $48 \mathrm{~h} 376$ incubation period (Fig. 3B). 377

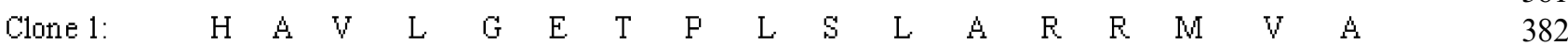

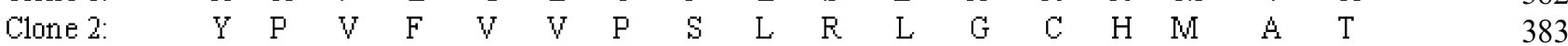

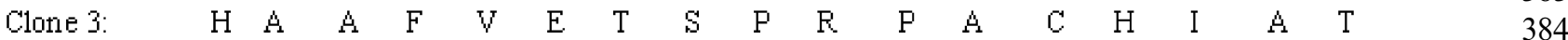

Fig. 1. Sequence analysis of rat iNOS highlighting random amino acid substitutions between our clone (clone 1, Accession No.: AY211532) and that 385 published by Nunokawa et al. (clone 2; Accession No.: D14051), and by Geng et al. (clone 3; Accession No.: X76881). 
A
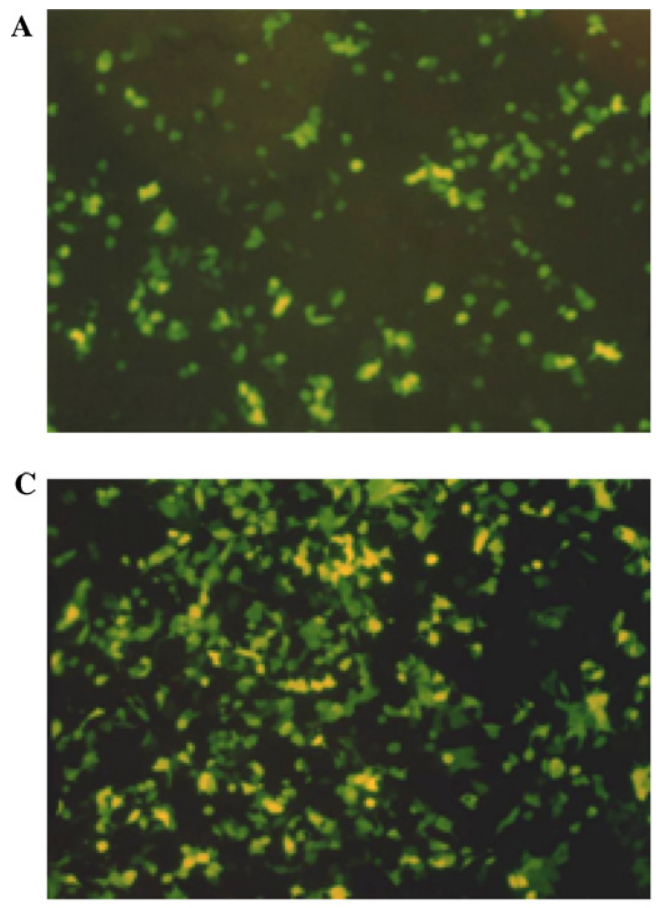

B
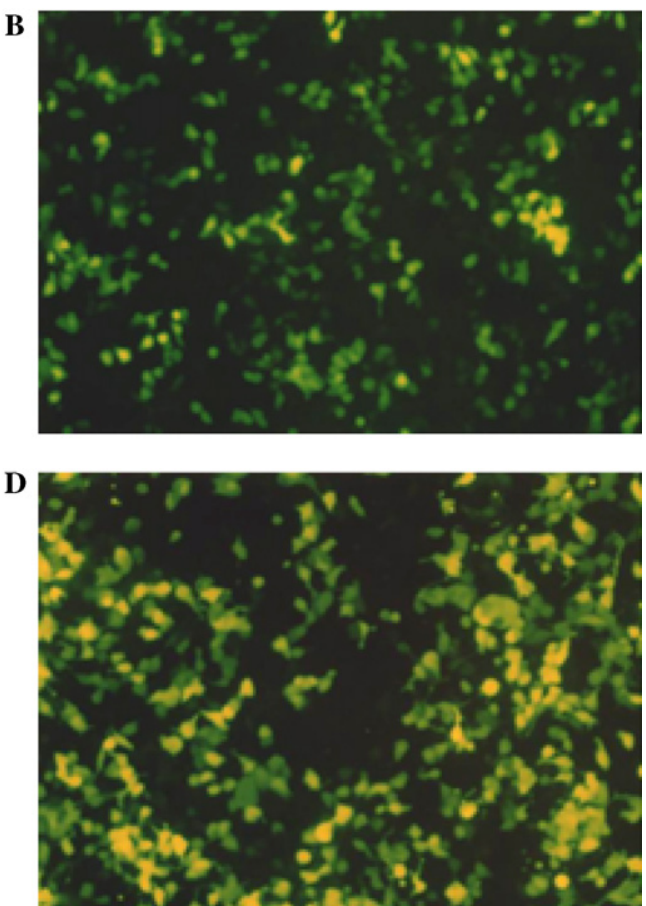

Fig. 2. Expression of iNOS-EGFP in HEK293 cells. Cells were transfected with pEGFP-N1 harbouring the iNOS cDNA construct as described in Experimental procedure. Cells were visualised at $6 \mathrm{~h} \mathrm{(A),} 12 \mathrm{~h}$ (B), $24 \mathrm{~h}$ (C), and $48 \mathrm{~h}$ (D) after transfection using a Nikon EFD3, LABOPHOT-2 fluorescence microscope. These pictures are representative of observations made in at least three different experiments.

A

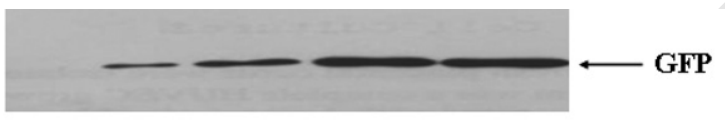

B

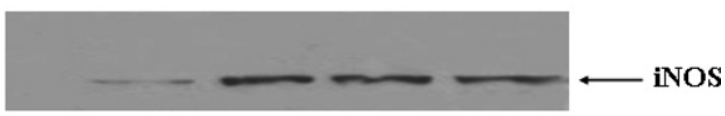

\section{Lanes: $\begin{array}{llllll}1 & 2 & 3 & 4 & 5\end{array}$}

Fig. 3. Time course of expression of GFP (A) and iNOS (B) in transfected HEK-293 cells. Lysates were obtained from control cells (lane 1) and at $6 \mathrm{~h}$ (lane 2), $12 \mathrm{~h}$ (lane 3), $24 \mathrm{~h}$ (lane 4), and $48 \mathrm{~h}$ (lane 5) after transfection with iNOS-pEGFP-N1. Proteins were separated by SDSPAGE electrophoresis and probed with either a monoclonal anti-GFP or anti-iNOS antibody as described in Experimental procedure. These blots are representative of three separate experiments using three different batches of cells.

\section{Effects of iNOS expression on nitrite production}

Transfection of cells with iNOS-pEGFP-N1, but not with empty or pEGFP-N1 vector, resulted in the expression of iNOS (Fig. 3B) and a marked increase in NO production which was reflected in a time-dependent increase in accumulated nitrite levels in the culture medium (Fig. 4A). Moreover the maximum amount of NO produced $\left(56 \pm 0.03 \mathrm{pmol} \mu \mathrm{g}\right.$ protein $^{-1}$ nitrite at $48 \mathrm{~h}$ ) was well within the range detected following induction of iNOS in various cells systems using inflammatory mediators such as bacterial lipopolysaccharide and/or cytokines. To confirm that the detected nitrite is gener- ated by iNOS, additional experiments were carried out 470 in which transfected cells were co-incubated with the 471 highly selective iNOS inhibitor GW274150. As shown in 472 Fig. 5A, accumulated nitrite production was abolished 473 by $10 \mu \mathrm{M}$ GW274150, confirming iNOS as the source of 474 the NO produced. 475

Effects of $i N O S$ expression on L-arginine transport

HEK-293 cells transported L- $\left[{ }^{3} \mathrm{H}\right]$ arginine in a time- 479 dependent manner which was linear over $5 \mathrm{~min}$ in both 480 transfected and non-transfected cells (data not shown). 481 As a result all subsequent uptake studies were carried 482 out over $1 \mathrm{~min}$. The rate of uptake in $48 \mathrm{~h}$ controls was 483 $1.91 \pm 0.03 \mathrm{pmol} \mu \mathrm{g}$ protein ${ }^{-1} \mathrm{~min}^{-1}$ and there was no sig- 484 nificant change in transporter activity in NO-generating 485 transfected cells expressing iNOS (Fig. 4B). Inhibition of 486 NO synthesis with GW274150 did not cause any signifi- 487 cant change in transport (Fig. 5B). Transfection of cells 488 with empty (data not shown) or pEGFP-N1 vector alone 489 did not alter L-arginine transport (Fig. 4B). 490

Profile of CAT expression and activity in HEK-293 cells 492

Total RNA isolated from HEK-293 cells was probed 494 by RT-PCR for CAT-1, CAT-2A, and CAT2B using iso- 495 form specific primers. The data obtained show that 496 HEK-293 cells express the high affinity CAT 1 and CAT 497 2B but not the low affinity CAT 2 A (Fig. 6). 


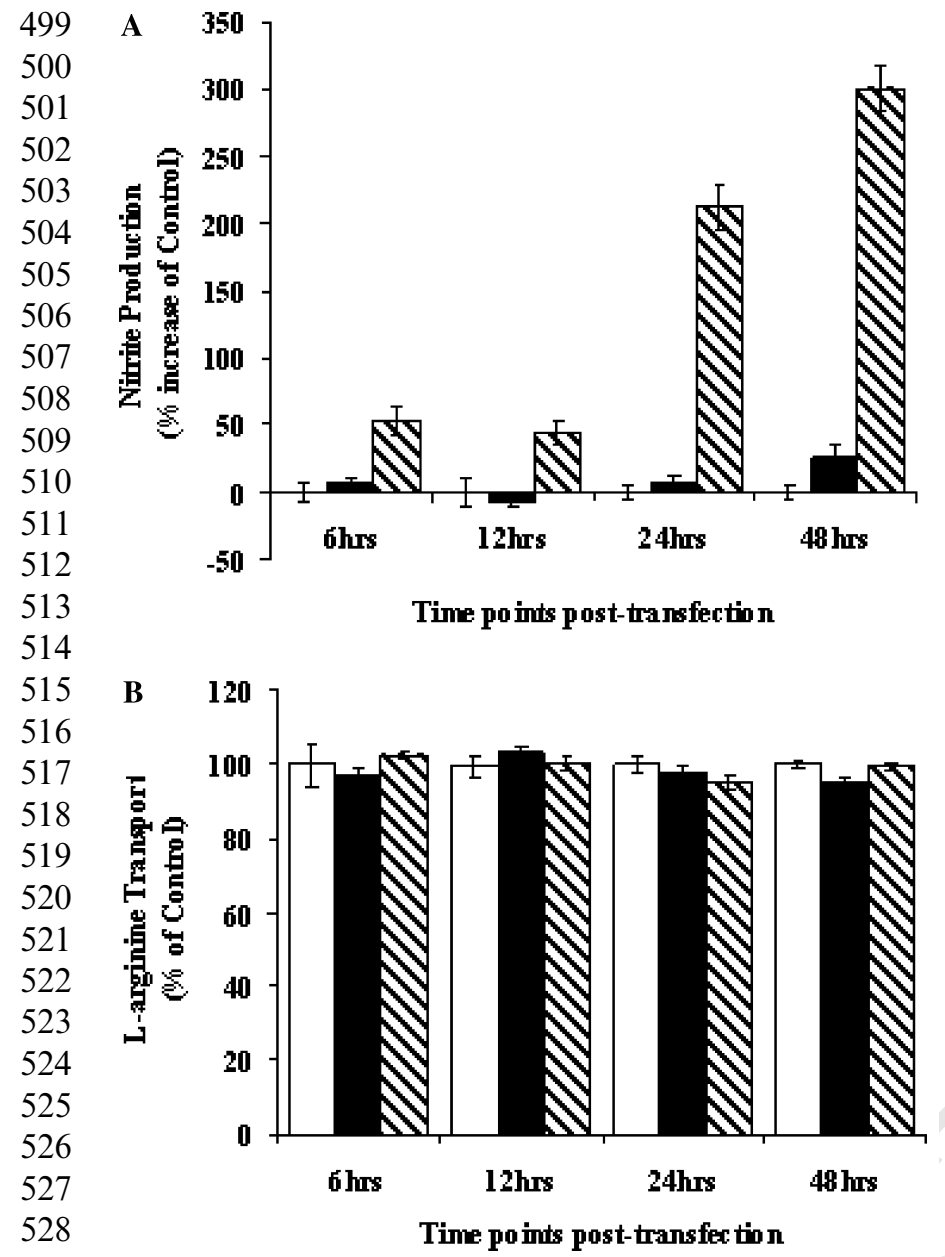

529

530

531

Fig. 4. Effects of iNOS-pEGFP-N1 transfection on NO production (A) and L-arginine transport (B) in HEK-293 cells. Nitrite and transport were measured at $6-48 \mathrm{~h}$ after transfection. Open bars represent control non-transfected cells, solid black bars represent cells transfected with a GFP only vector and hatched bars represent cells transfected with iNOS-pEGFP-N1. Results represent means \pm SEM of four separate experiments with six replicates in each.

In kinetic studies, entry of $\mathrm{L}$-arginine was monitored over the concentration range $5-1000 \mu \mathrm{M}$. Transport was found to be saturable (Fig. 7) with a $K_{\mathrm{m}}$ of $0.21 \mathrm{mM}$ and $V_{\max }$ of $5.3 \mathrm{nmol} \mu \mathrm{g}$ protein ${ }^{-1} \mathrm{~min}^{-1}$ and occurred via a single carrier system as evident from the Eadie-Hofstee plot in Fig. 7 (inset).

In competition experiments the substrate specificity of L-arginine transport was examined by screening the inhibitory effects of a series of $1 \mathrm{mM}$ unlabelled amino acids on uptake of $0.1 \mathrm{mM} \mathrm{L}-\left[{ }^{3} \mathrm{H}\right]$ arginine. As shown in Table 1, transport of L-arginine was unaffected by selective substrates for system A (preferred substrate: 2methylaminoisobutyric acid (MeAIB; [30]), ACS (preferred substrate: L-serine, L-alanine [31]), L (preferred substrate: 2-aminobicyclo-(2,2,1)heptane-2-carboxylic acid (BCH, [32]), and N (preferred substrate: 6-diazo-5oxo-L-norleucine (DON, [33]) but significantly inhibited by other cationic amino acids, L-lysine and L-ornithine

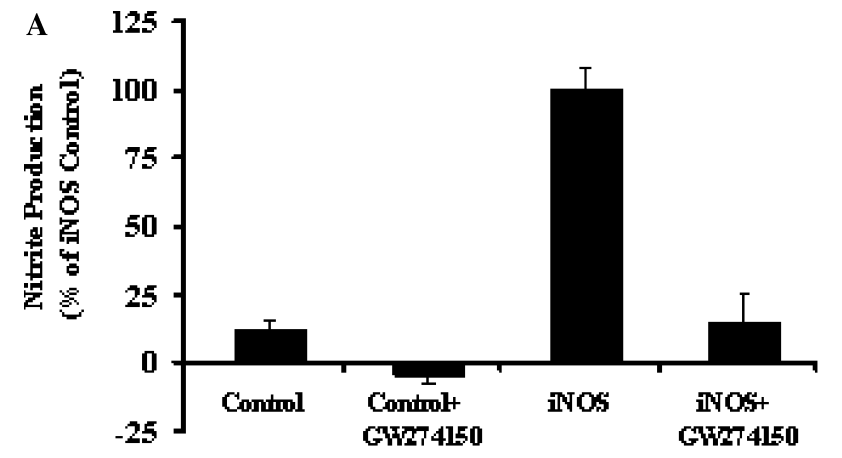

555

556

557

558

559

560

561

562

563

564

565

566

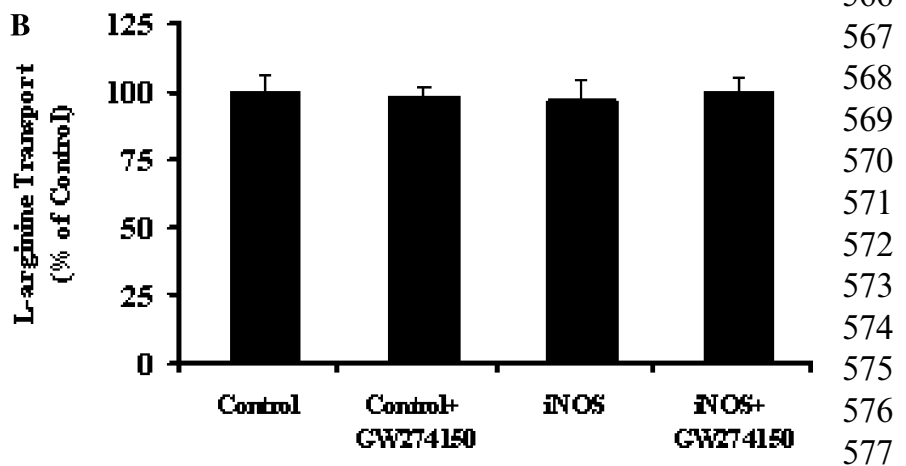

Fig. 5. Effect of GW274150 on NO production (A) and L-arginine 578 transport (B) in control and iNOS-pEGFP-N1 transfected HEK-293 579 cells. Nitrite and transport were measured $48 \mathrm{~h}$ after transfection. Results represent means \pm SEM of three separate experiments with two replicates in each.

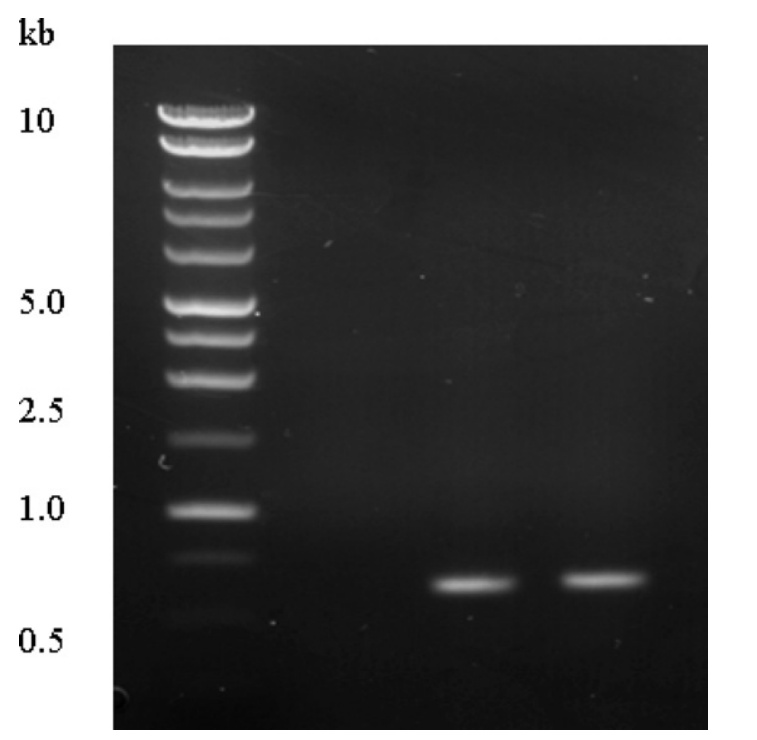

583

584

585

586

587

588

589

590

591

592

593

594

595

596

597

598

599

600

Fig. 6. CAT expression in HEK-293 cells. Total RNA was isolated 601 from control, non-activated cells and RT-PCR performed (33 cycles) 602 using primer pairs specific for CAT-1, CAT-2A, and CAT-2B as out- 603 lined in Experimental procedure. Lanes represent: $1=$ ladder, 604 $2=\mathrm{CAT}-2 \mathrm{~A}, 3=\mathrm{CAT}-2 \mathrm{~B}$, and $4=\mathrm{CAT}-1$.

(Table 1). In addition, transport was found to be 608 unaffected by changes in extracellular $\mathrm{Na}^{+}$or $\mathrm{pH}$ rang- 609 ing from 6 to 7.4 (Table 2). 
611

612

613

614

615

616

617

618

619

620

621

622

623

624

625

626

627

628

629

630

631

632

633

634

635

636

637

638

639

640

641

642

643

644

645

646

647

648

649

650

651

652

653

654

655

656

657

658

659

660

661

662

663

664

665

666

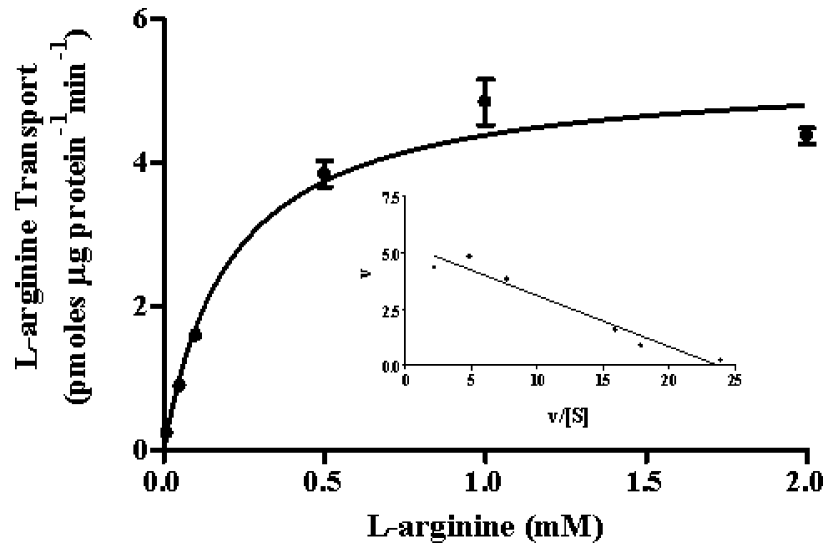

Fig. 7. Kinetics of L-arginine transport in HEK-293 cells. Rates of Larginine transport $(0.005-2 \mathrm{mM})$ were measured in control cells. The inset shows an Eadie-Hofstee plot of saturable transport, where $V$ is the initial velocity ( $\mathrm{pmol} \mu \mathrm{g}$ protein ${ }^{-1} \mathrm{~min}^{-1}$ ) and $\mathrm{S}$ is the substrate concentration $(\mathrm{mM})$. Values are means \pm SEM of three different experiments with six replicates in each.

Table 1

Selectivity of L-arginine transport in control HEK-293 cells

\begin{tabular}{ll}
\hline Condition & Transport rate $\left(\mathrm{pmol} \mu \mathrm{g}\right.$ protein $\left.{ }^{-1} \mathrm{~min}^{-1}\right)$ \\
\hline Control & $2.09 \pm 0.10$ \\
System AlASC substrates & \\
MeAIB & $2.56 \pm 0.14$ \\
Alanine & $2.57 \pm 0.12$ \\
Serine & $2.33 \pm 0.11$ \\
Proline & $2.03 \pm 0.09$
\end{tabular}

System $N$ substrates

DON $1.74 \pm 0.08$

L-Histidine $\quad 2.06 \pm 0.06$

System L substrates

$\mathrm{BCH}$

$1.96 \pm 0.13$

L-Phenylalanine $\quad 2.36 \pm 0.10$

L-Leucine $\quad 1.85 \pm 0.13$

System $y^{+}$substrates

$\begin{array}{ll}\text { L-Arginine } & 0.61 \pm 0.05^{*}\end{array}$

L-Lysine $\quad 0.91 \pm 0.05^{*}$

L-Ornithine $\quad 0.97 \pm 0.09^{*}$

Transport of $100 \mu \mathrm{M}$ L-arginine was measured over $1 \mathrm{~min}$ in the absence or presence of a 10 -fold excess $(1 \mathrm{mM})$ of a given inhibitor. Data are expressed as a percentage of the respective control influx in controls. Values are means $\pm \mathrm{SE}$ of three different experiments with six replicates in each.

${ }^{*} P<0.01$ relative to control.

\section{Discussion}

Production of NO by iNOS in several cell systems depends critically on the availability and transport of Larginine. More importantly, the expression of iNOS under these conditions is accompanied by a parallel upregulation in L-arginine transporter activity. This widely reported phenomenon [7,12,13,34-36] provides a mechanism for sustaining substrate supply during
Table 2

667

Effects of $\mathrm{Na}^{+}$and $\mathrm{pH}$ on L-arginine transport in HEK-293 cells

\begin{tabular}{lll}
\hline Condition & Transport rate $(\mathrm{pmol} \mu \mathrm{g}$ protein & \\
& & 669 \\
\hline
\end{tabular}

$\begin{array}{ll}\mathrm{Na}^{+} \text {-dependency } & 670\end{array}$

Control

$+\mathrm{Na}^{+} \quad 1.8 \pm 0.11$

$-\mathrm{Na}^{+} \quad 1.6 \pm 0.10$

671

672

673

pH-dependency

7.4 (control)

7.0

6.5

6.0

$1.85 \pm 0.08$

$1.89 \pm 0.11$

$1.86 \pm 0.06$

$1.82 \pm 0.12$

674

675

676

677

$\begin{array}{lll}\text { Transport of } 100 \mu \mathrm{M} \text { L-arginine was measured over } 1 \mathrm{~min} \text { in the pres- } & 678 \\ & 679\end{array}$ ence (normal Krebs solution) or absence of $\mathrm{Na}^{+}$and at varying $\mathrm{pH}$ values ranging from $\mathrm{pH} 7.4$ to $\mathrm{pH}$ 6). Data are expressed as a percentage of the respective control influx in controls. Values are means $\pm \mathrm{SE}$ of three different experiments with six replicates in each.

enhanced synthesis of NO, and is thus a key target for 684 regulating NO synthesis by iNOS. Previous work has, 685 however, not determined whether the increase in trans- 686 porter activity is a direct consequence of increased iNOS 687 activity resulting in enhanced substrate uptake into the 688 cells.

689

To resolve this question we have examined whether 690 transiently expressing iNOS in non-induced cells can 691 regulate the rate of $\mathrm{L}$-arginine transport as a conse- 692 quence of the increased utilisation of the amino acid for 693 NO synthesis. These studies were carried out in HEK- 694 293 cells transfected with an iNOS construct in pEGFP- 695 N1 vector using a synthetic peptide comprising of an 696 integrin-targeting ( $\alpha_{5} \beta_{1}$ integrin selective) arginine-gly- 697 cine-aspartic acid tripeptide motif and a DNA-binding 698 moiety of 16 lysine residues [22]. This novel transfection 699 strategy resulted in consistently high transfection 700 efficiency where $\geqslant 50 \%$ of cells appeared transfected. 701 More importantly, the levels of iNOS protein expressed 702 and the amounts of NO produced were comparable to 703 those detected in various cell systems following induc- 704 tion with pro-inflammatory mediators [7,10,13,35,36]. 705 This finding validates the use of peptide 6 as an effective 706 nonviral system for iNOS gene transfer in HEK-293 707 cells.

However, despite the prominent expression of iNOS 709 and marked production of NO achieved, parallel trans- 710 port studies failed to show any modification of L-argi- 711 nine transport: the transport rate in transfected cells was 712 not significantly different when compared to rates deter- 713 mined in control non-transfected cells. This observation 714 demonstrates that the expression of iNOS alone is not 715 sufficient to upregulate L-arginine uptake into cells. In 716 this regard, we and others have demonstrated that 717 increases in L-arginine transport are sensitive to inhibi- 718 tion by cycloheximide and associated with a marked 719 increase in the expression of transcripts for CATs, indi- 720 cating a critical requirement for protein synthesis of the 721 L-arginine transporter itself $[7,14,15,20,21]$. 
Our results therefore provide the first direct evidence that expression of active iNOS is by itself insufficient to upregulate CAT function and hence arginine transport. This conclusion is apparently in conflict with a recent report by Hammermann et al. [18], which suggests that direct inhibition of iNOS activity in rat alveolar macrophages is sufficient to abolish LPS-activated L-arginine uptake. The inhibitor of iNOS primarily used in those experiments (AMT) did not inhibit basal arginine influx in control cells but inhibited enhanced arginine uptake in LPS-pretreated cells even with brief pre-incubations. The authors therefore concluded that this was an indirect effect due to reduced arginine utilisation by iNOS. This association is however questionable since L-arginine transport: (i) occurs by facilitated diffusion driven by the membrane potential, (ii) accumulates L-arginine against a concentration gradient, and (iii) is sensitive to transstimulation when substrate concentrations are high on the opposite side of the cell membrane [37,38]. Thus, if inhibition of L-arginine utilisation by iNOS results in elevated intracellular levels of this amino acid, entry of radiolabelled $\mathrm{L}$-arginine would be enhanced via transstimulation causing an increase in $\mathrm{L}-\left[{ }^{3} \mathrm{H}\right]$ arginine uptake. As we observed no significant changes in accumulated L$\left[{ }^{3} \mathrm{H}\right]$ arginine in cells transfected with our iNOS construct, we conclude that activation of iNOS itself does not influence rates of L-arginine transport. It could be argued that in the system used by Hammermann et al. [18], activation of cells may result in the co-induction of linker proteins which may facilitate compartmentalised regulation of L-arginine transport and NO synthesis. This, however, still remains to be established and the coupling of L-arginine transport to NO synthesis may not be a widespread phenomenon in all activated cell types [13,20,21].

Differences in the profile of expression of L-arginine transporter systems may explain the discrepancy between our study and those of Hammermann et al. [18]. This latter point is important since there are suggestions in the literature that CATs may be linked to different NOS enzymes, thereby providing a direct supply of substrate for that isoform. In this regard, CAT-1 is thought to supply substrate to endothelial NOS by virtue of its co-localisation with this enzyme [39]. CAT-2B on the other hand may regulate supply of L-arginine to iNOS as these proteins are co-induced in cells where neither is constitutively expressed. Moreover, in such systems, the induction of CAT-2B can be accompanied by a parallel downregulation in CAT-1 mRNA [14], thereby making CAT-2B the critical transporter in these cells.

Since the nature of the transporters associated with Larginine uptake had not previously been characterised in HEK-293 cells, we have therefore examined the characteristics of L-arginine transport and the profile of expression of CATs in these cells. Kinetic studies and EadieHofstee analysis show that entry of L-arginine occurs predominantly via a single saturable carrier that is of rel- 779 atively low capacity but of high affinity for L-arginine. 780 Transport was selectively inhibited by the cationic 781 amino acids L-lysine, L-ornithine, and by L-arginine itself. 782 Substrates for amino acid transport systems A/ASC, N, 783 and $\mathrm{L}$ were without significant effect. This inhibition 784 profile together with the $\mathrm{Na}^{+}$and $\mathrm{pH}$ insensitivity 785 strongly implicate the CATs as the predominant carrier 786 of L-arginine in HEK-293 cells and excludes other sys- 787 tems such as $\mathrm{y}^{+} \mathrm{L}, \mathrm{b}^{\mathrm{o},+}$, and $\mathrm{B}^{\mathrm{o},+}$ which are broad scope in 788 nature, transporting both cationic and neutral amino 789 acids $[38,40]$.

To identify the CAT or CATs expressed in HEK-293 791 cells we carried out RT-PCR of total RNA isolated from 792 these cells using CAT-1, CAT-2A, and CAT-2B-specific 793 primers respectively. CAT-3 was not investigated since 794 this transporter is thought to be expressed predomi- 795 nantly in brain [41,42] and thymus tissue [43] and also 796 interacts with neutral amino acids [41]. The data 797 obtained show that HEK-293 cells express transcripts 798 for CAT-1 and CAT-2B but not for CAT-2A. This 799 expression profile agrees with the functional studies in 800 that the kinetics of uptake reflects a high affinity system 801 or systems with indistinguishable characteristics at the 802 functional level. Although, CAT-2A and CAT-2B are 803 spliced variants with high percentage structural homol- 804 ogy they are functionally distinguishable by virtue of the 805 fact that CAT-2A is a high capacity but low affinity car- 806 rier while CAT-2B exhibits similar functional character- 807 istics to those of CAT-1 [44-46]. Both these carriers have 808 a high affinity for L-arginine, transporting the latter with 809 a Michaelis constant $\left(K_{\mathrm{m}}\right)$ of between 0.14 and $0.38 \mathrm{mM} .810$ The $K_{\mathrm{m}}$ of $0.21 \mathrm{mM}$ determined in our study therefore 811 supports CAT-1 and CAT-2B as being the predominant 812 carriers of L-arginine into HEK-293 cells.

At present we cannot distinguish between CAT-1 and 814 CAT-2B in terms of their relative contribution to total L- 815 arginine uptake nor can we specify which CAT directly 816 supplies L-arginine to transfected iNOS in our cell sys- 817 tem. However, the detection of CAT-2B transcripts, gen- 818 erally believed to be expressed under inflammatory 819 conditions in parallel with iNOS, suggests that this pro- 820 tein can exist endogenously in control conditions and 821 may not require induction. More importantly, its detec- 822 tion excludes the possibility that iNOS was not able to 823 alter transport in our studies because of lack of expres- 824 sion of the critical CAT (CAT-2B) associated with 825 uptake of L-arginine for utilisation by this enzyme. $\quad 826$

In conclusion, our current findings provide the first 827 direct evidence that CATs function independently of 828 iNOS and that the rate of transport of L-arginine into 829 cells is not modulated by the activity of iNOS. Thus, the 830 enhancement in L-arginine transport observed in systems 831 where expression of iNOS and the subsequent genera- 832 tion of large quantities of $\mathrm{NO}$ are induced must occur 833 via mechanisms not directly related to the rate of con- 834 
sumption of L-arginine or generation of NO by iNOS. These mechanisms presumably involve activation by external stimuli of common upstream signalling pathways leading to upregulation of iNOS and CAT expression [15].

\section{Acknowledgment}

We gratefully acknowledge the support of the British Heart Foundation (PG/98130).

\section{References}

[1] R.G. Kilbourn, A. Jubran, S.S. Gross, O.W. Griffith, R. Levi, J. Adams, R.F. Lodato, Reversal of endotoxin-mediated shock by $N^{\mathrm{G}}$-methyl-L-arginine, an inhibitor of nitric oxide synthesis, Biochem. Biophys. Res. Commun. 172 (1990) 1132-1138.

[2] C.E. Wright, D.D. Rees, S. Moncada, Protective and pathological roles of nitric oxide in endotoxin shock, Cardiovasc. Res. 26 (1992) 48-57.

[3] C. Thiemermann, Nitric oxide and septic shock, Gen. Pharmacol. 29 (1997) 159-166.

[4] P.J. Barnes, Nitric oxide and asthma, Res. Immunol. 146 (1995) 698-702.

[5] I. Alican, P. Kubes, A critical role for nitric oxide in intestinal barrier function and dysfunction, Am. J. Physiol. 270 (1996) G225G237.

[6] D. Beasley, J.H. Schwartz, B.M. Brenner, Interleukin 1 induces prolonged L-arginine-dependent cyclic guanosine monophosphate and nitrite production in rat vascular smooth muscle cells, J. Clin. Invest. 87 (1991) 602-608.

[7] R.G. Bogle, A.R. Baydoun, J.D. Pearson, S. Moncada, G.E. Mann, $\mathrm{L}$-Arginine transport is increased in macrophages generating nitric oxide, Biochem. J. 284 (1992) 15-18.

[8] C.A. Schott, G.A. Gray, J.-C. Stoclet, Dependence of endotoxininduced vascular hyporeactivity on extracellular L-arginine, Br. J. Pharmacol. 108 (1993) 38-43.

[9] A.R. Baydoun, R.G. Bogle, J.D. Pearson, G.E. Mann, Discrimination between citrulline and arginine transport in activated murine macrophages: inefficient synthesis of NO from recycling of citrulline to arginine, Br. J. Pharmacol. 112 (1994) 487-492.

[10] E.I. Closs, J.S. Scheld, M. Sharafi, U. Forstermann, Substrate supply for nitric-oxide synthase in macrophages and endothelial cells: role of cationic amino acid transporters, Mol. Pharmacol. 57 (2000) 68-74.

[11] H. Sato, M. Fujiwara, S. Bannai, Effect of lipopolysaccharide on transport and metabolism of arginine in mouse peritoneal macrophages, J. Leukoc. Biol. 52 (1992) 161-164.

[12] W. Durante, L. Liao, A.I. Schafer, Differential regulation of L-arginine transport and inducible NOS in cultured vascular smooth muscle cells, Am. J. Physiol. 268 (1995) H1158-H1164.

[13] S.M. Wileman, G.E. Mann, A.R. Baydoun, Induction of L-arginine transport and nitric oxide synthase in vascular smooth muscle cells: synergistic actions of pro-inflammatory cytokines and bacterial lipopolysaccharide, Br. J. Pharmacol. 116 (1995) 3243-3250.

[14] D.K. Kakuda, M.J. Sweet, C.L. Mac Leod, D.A. Hume, D. Markovich, CAT2-mediated L-arginine transport and nitric oxide production in activated macrophages, Biochem. J. 340 (1999) 549553.

[15] A.R. Baydoun, S.M. Wileman, C.P. Wheeler-Jones, M.S. Marber, G.E. Mann, J.D. Pearson, E.I. Closs, Transmembrane signalling mechanisms regulating expression of cationic amino acid trans- porters and inducible nitric oxide synthase in rat vascular smooth 893 muscle cells, Biochem. J. 344 (1999) 265-272. 894

[16] M. Nakane, V. Klinghofer, J.E. Kuk, J.L. Donnelly, G.P. Budzik, 895 J.S. Pollock, F. Basha, G.W. Carter, Novel potent and selective 896 inhibitors of inducible nitric oxide synthase, Mol. Pharmacol. 47897 (1995) 831-834.

[17] G.J. Southan, C. Szabó, C. Thiemermann, Isothioureas: potent 899 inhibitors of nitric oxide synthases with variable isoform selectiv- 900 ity, Br. J. Pharmacol. 114 (1995) 510-516.

901

[18] R. Hammermann, C. Stichnote, E.I. Closs, H. Nawrath, K. Racke, 902 Inhibition of nitric oxide synthase abrogates lipopolysaccharides- 903 induced up-regulation of L-arginine uptake in rat alveolar macro- 904 phages, Br. J. Pharmacol. 133 (2001) 379-386. 905

[19] R. Hammermann, M.D. Dreissig, J. Mossner, M. Fuhrmann, L. 906 Berrino, M. Gothert, K. Racke, Nuclear factor-kappaB mediates 907 simultaneous induction of inducible nitric-oxide synthase and up- 908 regulation of the cationic amino acid transporter CAT-2B in rat 909 alveolar macrophages, Mol. Pharmacol. 58 (2000) 1294-1302. 910

[20] A.R. Baydoun, R.G. Bogle, J.D. Pearson, G.E. Mann, Selective 911 inhibition by dexamethasone of induction of NO synthase, but 912 not of induction of L-arginine transport, in activated murine mac- 913 rophage J774 cells, Br. J. Pharmacol. 110 (1993) 1401-1406. 914

[21] D.J. Gill, B.C. Low, M.R. Grigor, Interleukin-1beta and tumor 915 necrosis factor-alpha stimulate the cat-2 gene of the L-arginine 916 transporter in cultured vascular smooth muscle cells, J. Biol. 917 Chem. 271 (1996) 11280-11283.

[22] S.L. Hart, C.V. Arancibia-Carcamo, M.A. Wolfert, C. Mailhos, 919 N.J. O'Reilly, R.R. Ali, C. Coutelle, A.J. George, R.P. Harbottle, 920 A.M. Knight, D.F. Larkin, R.J. Levinsky, L.W. Seymour, A.J. 921 Thrasher, C. Kinnon, Lipid-mediated enhancement of transfec- 922 tion by a nonviral integrin-targeting vector, Hum. Gene Ther. 9923 (1998) 575-585.

[23] R.J. Young, R.M. Beams, K. Carter, H.A. Clark, D.M. Coe, C.L. 925 Chambers, P.I. Davies, J. Dawson, M.J. Drysdale, K.W. Franz- 926 man, C. French, S.T. Hodgson, H.F. Hodson, S. Kleanthous, P. 927 Rider, D. Sanders, D.A. Sawyer, K.J. Scott, B.G. Shearer, R. 928 Stocker, S. Smith, M.C. Tackley, R.G. Knowles, Inhibition of 929 inducible nitric oxide synthase by acetamidine derivatives of het- 930 ero-substituted lysine and homolysine, Bioorg. Med. Chem. Lett. 931 10 (2000) 597-600.

932

[24] A.R. Baydoun, D.M. Morgan, Inhibition of ornithine decarboxyl- 933 ase potentiates nitric oxide production in LPS-activated J774 cells, 934 Br. J. Pharmacol. 125 (1998) 1511-1516. 935

[25] L.C. Green, D.A. Wagner, J. Glogowski, P.L. Skipper, J.S. Wish- 936 nok, S.R. Tannenbaum, Analysis of nitrate, nitrite, and 937 $\left[{ }^{15} \mathrm{~N}\right]$ nitrate in biological fluids, Anal. Biochem. 126 (1982) 131- 938 138.

[26] Y. Nunokawa, N. Ishida, S. Tanaka, Cloning of inducible nitric 940 oxide synthase in rat vascular smooth muscle cells, Biochem. Bio- 941 phys. Res. Commun. 191 (1993) 89-94. 942

[27] Y. Geng, M. Almqvist, G.K. Hansson, cDNA cloning and expres- 943 sion of inducible nitric oxide synthase from rat vascular smooth 944 muscle cells, Biochim. Biophys. Acta 1218 (1994) 421-424. 945

[28] V. Adams, S. Krabbes, H. Jiang, J. Yu, A. Rahmel, S. Gielen, G. 946 Schuler, R. Hambrecht, Complete coding sequence of inducible 947 nitric oxide synthase from human heart and skeletal muscle of 948 patients with chronic heart failure, Nitric Oxide 2 (1998) 242- 949 249.

[29] C.R. Lyons, G.J. Orloff, J.M. Cunningham, Molecular cloning and 951 functional expression of an inducible nitric oxide synthase from a 952 murine macrophage cell line, J. Biol. Chem. 267 (1992) 6370-6374. 953

[30] G.C. Gazzola, V. Dall'Asta, G.G. Guidotti, The transport of neu- 954 tral amino acids in cultured human fibroblasts, J. Biol. Chem. 255955 (1980) 929-936.

[31] R. Franchi-Gazzola, G.C. Gazzola, V. Dall'Asta, G.G. Guidotti, 957 The transport of alanine, serine, and cysteine in cultured human 958 fibroblasts, J. Biol. Chem. 257 (1982) 9582-9587. 
[32] H.N. Christensen, M.E. Handlogten, I. Lam, H.S. Tager, R. Zand, A bicyclic amino acid to improve discriminations among transport systems, J. Biol. Chem. 244 (1969) 1510-1520.

[33] L. Goldstein, Glutamine transport by mitochondria isolated from normal and acidotic rats, Am. J. Physiol. 229 (1975) 1027-1033.

[34] A. Schmidlin, H. Wiesinger, Transport of L-arginine in cultured glial cells, Glia 11 (1994) 262-268.

[35] B.R. Stevens, D.K. Kakuda, K. Yu, M. Waters, C.B. Vo, M.K. Raizada, Induced nitric oxide synthesis is dependent on induced alternatively spliced CAT-2 encoding L-arginine transport in brain astrocytes, J. Biol. Chem. 271 (1996) 24017-24022.

[36] W.W. Simmons, E.I. Closs, J.M. Cunningham, T.W. Smith, R.A. Kelly, Cytokines and insulin induce cationic amino acid transporter (CAT) expression in cardiac myocytes. Regulation of Larginine transport and no production by CAT-1, CAT-2A, and CAT-2B, J. Biol. Chem. 271 (1996) 11694-11702.

[37] O. Bussolati, P.C. Laris, F.A. Nucci, V. Dall'Asta, N. Longo, G.G. Guidotti, G.C. Gazzola, Dependence of L-arginine accumulation on membrane potential in cultured human fibroblasts, Am. J. Physiol. 253 (1987) C391-C397.

[38] M.F. White, The transport of cationic amino acids across the plasma membrane of mammalian cells, Biochim. Biophys. Acta 822 (1985) 355-374.

[39] K.K. McDonald, S. Zharikov, E.R. Block, M.S. Kilberg, A caveolar complex between the cationic amino acid transporter 1 and endothelial nitric-oxide synthase may explain the "arginine para- 985 dox," J. Biol. Chem. 272 (1997) 31213-31216.

[40] R. Deves, C.A. Boyd, Transporters for cationic amino acids in ani- 987 mal cells: discovery, structure, and function, Physiol. Rev. 78988 (1998) 487-545.

[41] K. Ito, M. Groudine, A new member of the cationic amino acid 990 transporter family is preferentially expressed in adult mouse brain, 991 J. Biol. Chem. 272 (1997) 26780-26786.

[42] H. Hosokawa, T. Sawamura, S. Kobayashi, H. Ninomiya, S. Miwa, 993 T. Masaki, Cloning and characterization of a brain-specific cationic 994 amino acid transporter, J. Biol. Chem. 272 (1997) 8717-8722. 995

[43] N. Vekony, S. Wolf, J.P. Boissel, K. Gnauert, E.I. Closs, Human cat- 996 ionic amino acid transporter hCAT-3 is preferentially expressed in 997 peripheral tissues, Biochemistry 40 (2001) 12387-12394. 998

[44] E.I. Closs, L.M. Albritton, J.W. Kim, J.M. Cunningham, Identifi- 999 cation of a low affinity, high capacity transporter of cationic 1000 amino acids in mouse liver, J. Biol. Chem. 268 (1993) 7538-7544. 1001

[45] E.I. Closs, C.R. Lyons, C. Kelly, J.M. Cunningham, Characteriza- 1002 tion of the third member of the MCAT family of cationic amino 1003 acid transporters. Identification of a domain that determines the 1004 transport properties of the MCAT proteins, J. Biol. Chem. 2681005 (1993) 20796-20800.

1006

[46] E.I. Closs, Expression, regulation and function of carrier proteins 1007 for cationic amino acids, Curr. Opin. Nephrol. Hypertens. 111008 (2002) 99-107. 